\title{
Isolated Optic Disc Tuberculosis
}

\author{
Ahmad M. Mansour ${ }^{\mathrm{a}, \mathrm{c}}$ Khalid F. Tabbara ${ }^{\mathrm{e}-\mathrm{g}}$ Zuhair Tabbarah $^{\mathrm{b}, \mathrm{d}}$ \\ ${ }^{a}$ Department of Ophthalmology, and ${ }^{b}$ Department of Internal Medicine, Infectious Disease \\ Service, American University of Beirut, and Departments of ${ }^{\mathrm{C}}$ Ophthalmology and ${ }^{\mathrm{d}}$ Internal \\ Medicine, Rafic Hariri University Hospital, Beirut, Lebanon; ${ }^{\mathrm{e}}$ The Eye Center and the Eye \\ Foundation for Research in Ophthalmology, and 'Department of Ophthalmology, College \\ of Medicine, King Saud University, Riyadh, Saudi Arabia; ${ }^{9}$ The Wilmer Ophthalmological \\ Institute of the Johns Hopkins University School of Medicine, Baltimore, Md., USA
}

\section{Key Words}

Optic neuropathy $\cdot$ Ocular tuberculosis $\cdot$ Systemic tuberculosis $\cdot$ Immunocompetence

\begin{abstract}
We present a healthy male subject who developed progressive visual loss in the left eye initially diagnosed as optic neuritis. Upon suspicion of infectious etiology, testing was positive for tuberculosis. There were no signs or symptoms of active systemic tuberculosis infection. The patient responded swiftly to antimycobacterial therapy with return of vision and resolution of disc swelling. Positive purified protein derivative skin test, negative chest radiograph, negative systemic workup, negative workup for other causes of unilateral optic neuritis and quick response to mycobacterial therapy reaffirm the entity of isolated optic disc tuberculosis similar to isolated choroidal tuberculosis without systemic manifestation. ( $2015 \mathrm{~S}$. Karger AG, Basel
\end{abstract}

\section{Case Report}

This 34-year-old man had progressive visual loss in the left eye of 2 months. He was diagnosed with left optic neuritis, and systemic corticosteroids were prescribed. Magnetic resonance imaging of the brain was normal. Automated visual fields were symmetrically normal. After seeking a second opinion 14 days later, best-corrected visual acuity (BCVA) of the left eye was 20/100 (6/30) with diffuse disc elevation and peripapillary nerve fiber hemorrhage (fig. 1a). There was absence of anterior chamber or vitreous flare and cells. He had no afferent pupillary defect and no red color desaturation. He had fluorescein dye leakage from the optic disc (fig. 2a). There was no evidence of retinal vasculitis. Optical coherence tomography (OCT) demonstrated optic nerve head swelling and thickening (fig. 3a).

KARGER 125/s $\quad \begin{aligned} & \text { Ahmad M. Mansour MD } \\ & \text { Department of Ophthalmology, American University of Beirut } \\ & \text { PO Box } 1136044 \\ & \text { Beirut (Lebanon) } \\ & \text { E-Mail ammansourmd@gmail.com }\end{aligned}$


Mansour et al.: Isolated Optic Disc Tuberculosis

Visual acuity was normal in the right eye with negative findings by 90-diopter slit-lamp exam, visual acuity, OCT, and fluorescein angiography. Detailed medical history was positive for a cough productive of clear sputum of recent duration, nonsmoking status, no exposure to cats, no ingestion of raw meat, and no extramarital relations. Tuberculosis was suspected. Physical exam and infectious workup were essentially negative (HIV, VDRL, Borrelia burgdorferi, Brucella, angiotensin-converting enzyme) including chest radiograph and chest CT. Purified protein derivative (PPD) skin test was strongly positive. Ten days after the initial consult, BCVA deteriorated further to 20/200 (6/60) in the left eye with increased disc swelling. He was started on treatment for presumed optic disc tuberculoma consisting of 2 months of rifampin, isoniazid, pyrazinamide, and ethambutol (respective doses: 150, 75, 400 , and $275 \mathrm{mg}$ ) followed by 4 months of rifampin and isoniazid. One week after initiation of quadruple antituberculous therapy, vision improved to 20/30 (6/9) with decreased disc swelling. BCVA in the left eye was 20/20 (6/6) 2 weeks after initiation of therapy with a marked decrease in both disc elevation (fig. 1b) and fluorescein leakage (fig. 2b). Three months after initiation of therapy, funduscopy and OCT (fig. 3b) returned to normal. At follow-up 4 months after initiation of therapy, visual fields were unchanged. At the last followup 10 months after initiation of therapy, clinical examination was unchanged.

\section{Discussion}

Optic nerve tuberculomas are rarely reported [1-6], and their natural history, prognosis, and duration of required treatment remain unclear. Davis et al. [1] gathered a large series of optic disc tuberculosis in order to delineate the progress of the disease and propose the most authoritative therapeutic regimen.

In this analysis of 62 eyes from 49 patients with tuberculous optic neuropathy, papillitis was present in $51.6 \%$, neuroretinitis in $14.5 \%$, and optic nerve tubercle in $11.3 \%$, with uveitis absent in $11.3 \%$ and extraocular tuberculosis absent in $63.3 \%$ of patients [1]. In our case, antituberculosis therapy was initiated, based on clinical evidence. The ocular findings improved remarkably with the antituberculosis treatment. An index of suspicion is required to diagnose ocular tuberculosis when all other systemic investigations are negative, especially in this part of the world where tuberculosis is endemic.

Isolated optic disc tuberculosis [1-6], similar to isolated choroidal [7] or ciliary body [8] tuberculosis, can be the presenting form of tuberculosis in immunocompetent subjects without extraocular clinical signs or symptoms. Tuberculosis should be considered in the diagnosis of papillitis, even in asymptomatic patients. Positive PPD skin test and rapid response to antimycobacterial therapy confirm the clinical diagnosis of presumed ocular tuberculosis [9].

\section{Statement of Ethics}

The authors have no ethical conflicts to disclose.

\section{Disclosure Statement}

The authors report no conflict of interests and did not receive funding support. Ahmad M. Mansour is a consultant for Bayer. 
Case Reports in

Ophthalmology

\begin{tabular}{l|l}
\hline \multicolumn{2}{l}{ Case Rep Ophthalmol 2015;6:317-320 } \\
\hline DOI: $10.1159 / 000439376$ & $\begin{array}{l}\text { ○ 2015 S. Karger AG, Basel } \\
\text { www.karger.com/cop }\end{array}$ \\
\hline
\end{tabular}

Mansour et al.: Isolated Optic Disc Tuberculosis

\section{References}

1 Davis EJ, Rathinam SR, Okada AA, Tow SL, Petrushkin H, Graham EM, Chee S-P, Guex-Crosier Y, Jakob E, Tugal-Tutkun I, Cunningham ET Jr, Leavitt JA, Mansour AM, Winthrop KL, Hills WL, Smith JR: Clinical spectrum of tuberculous optic neuropathy. J Ophthalmic Inflamm Infect 2012;2:183-189.

-2 Wan Hazabbah WH, Rohaizan Y, Shatriah I: Isolated optic neuritis secondary to presumed tuberculosis in an immunocompetent child. Med J Malaysia 2012;67:102-104.

3 Mansour AM: Optic disc tubercle. J Neuroophthalmol 1998;18:201-203.

-4 Ooi YL, Tai LY, Subrayan V, Tajunisah I: Combined optic neuropathy and central retinal artery occlusion in presumed ocular tuberculosis without detectable systemic infection. Ocul Immunol Inflamm 2011;19:370372.

-5 Asensio-Sánchez VM, Torreblanca-Agüera B, Martínez-Calvo S, Calvo MJ, Rodríguez R: Tuberculous papillitis (in Spanish). Arch Soc Esp Oftalmol 2006;81:37-39.

6 Shetty SB, Bawtag MA, Biswas J: A case of subretinal tubercular abscess presenting as disc edema. Indian J Ophthalmol 2015;63:164-166.

7 Mansour AM, Haymond R: Choroidal tuberculomas without evidence of extraocular tuberculosis. Graefes Arch Clin Exp Ophthalmol 1990;228:382-383.

-8 Al-Fraikh H, Al-Dahmash S: Rare presentation of definitive ocular tuberculosis in an immunocompetent young patient. Saudi J Ophthalmol 2010;24:31-33.

-9 Bodaghi B, LeHoang P: Ocular tuberculosis. Curr Opin Ophthalmol 2000;11:443-448.
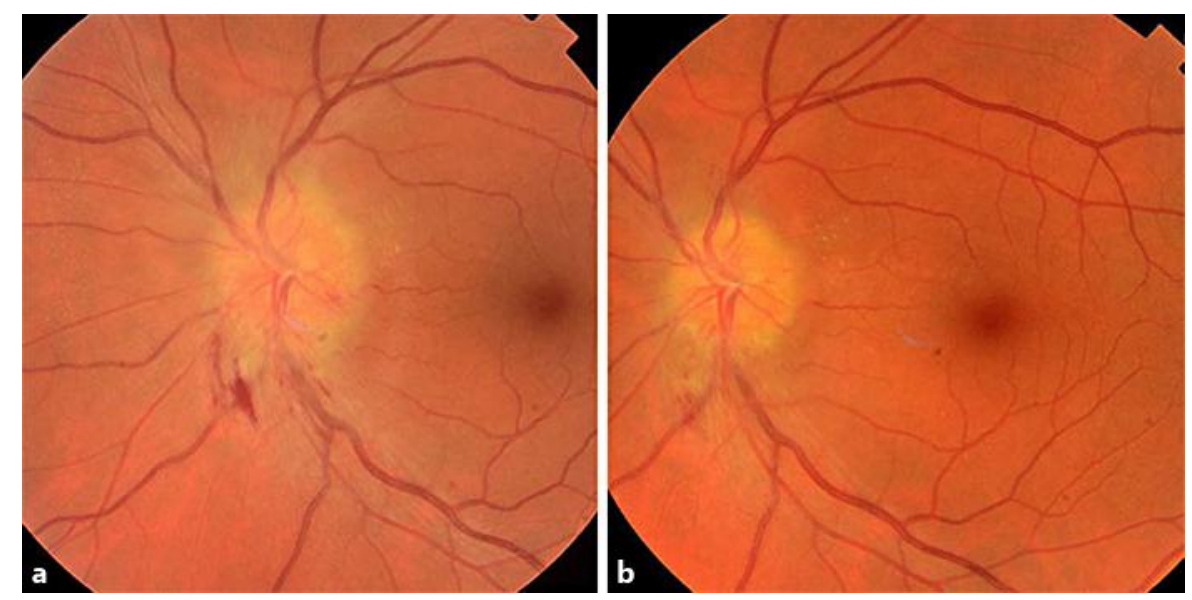

Fig. 1. a Fundus photograph. Posterior pole of the left eye demonstrates marked swelling of the optic disc with peripapillary hemorrhage. b Fundus photograph. Posterior pole of the left eye 2 weeks after initiation of antimycobacterial therapy shows marked resolution of the optic disc swelling. 


\section{Case Reports in \\ Ophthalmology}

\begin{tabular}{l|l}
\hline \multicolumn{2}{l}{ Case Rep Ophthalmol 2015;6:317-320 } \\
\hline DOI: 10.1159/000439376 & $\begin{array}{l}\text { ○ 2015 S. Karger AG, Basel } \\
\text { www.karger.com/cop }\end{array}$ \\
\hline
\end{tabular}

Mansour et al.: Isolated Optic Disc Tuberculosis
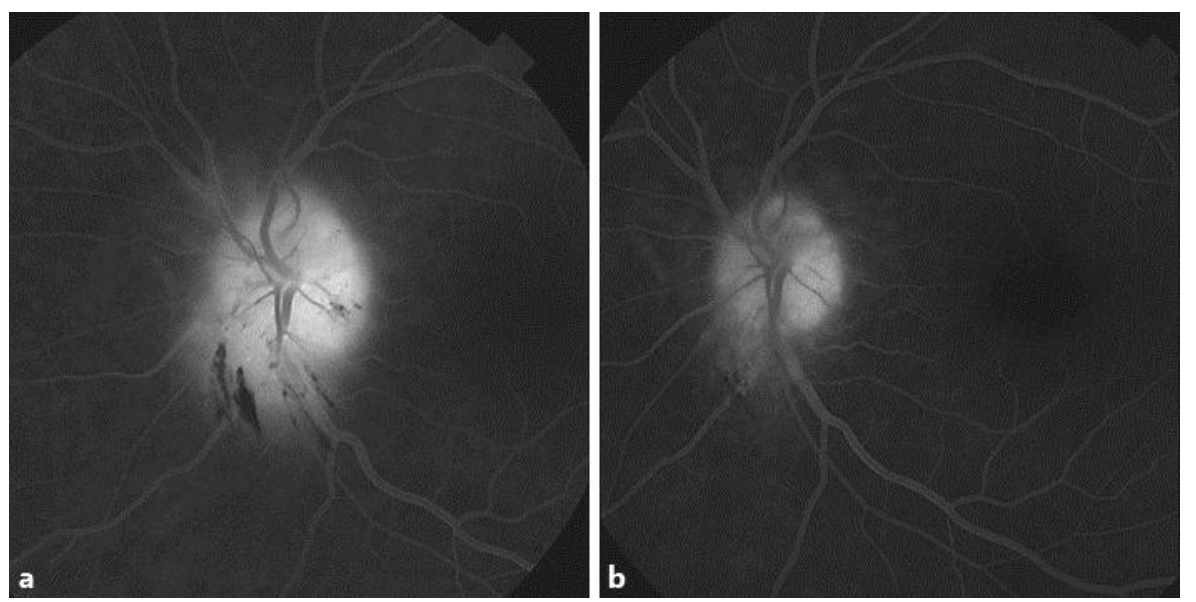

Fig. 2. a Intravenous fluorescein angiography ( 6 min $21 \mathrm{~s}$ after dye injection). The left optic disc shows profuse leakage well at the venous phase transit. $\mathbf{b}$ Intravenous fluorescein angiography (8 min after dye injection). The left disc shows minimal leakage at the venous phase transit 2 weeks after initiation of therapy.
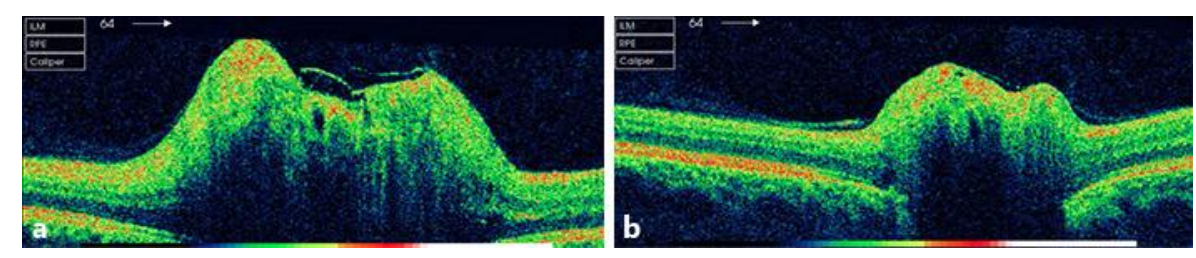

Fig. 3. a OCT. Horizontal scan through the center of the left optic disc shows marked swelling of optic nerve head. b OCT. Horizontal scan through the center of the left optic disc 3 months after initiation of therapy. The left disc swelling has resolved. 